\title{
Research Paper: Family-Centered Services by Medical and Rehabilitation Staff: A Descriptive Study
}

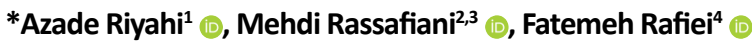 \\ 1. Department of Occupational Therapy, School of Rehabilitation, Arak University of Medical Sciences, Arak, Iran. \\ 2. Department of Occupational Therapy, Health Science Center, Kuwait University, Kuwait, Kuwait. \\ 3. Pediatric Neurorehabilitation Research Center, University of Social Welfare and Rehabilitation Sciences, Tehran, Iran. \\ 4. Department of Biostatistics, School of Health, Arak University of Medical Sciences, Arak, Iran.
}

\begin{tabular}{|c|c|}
\hline 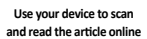 & \\
\hline 口䀅回 & ditation Riyahi A, Rassafiani M, Rafiei F. [Family-Centered Services by Medical and Rehabilitation Staff: A Descriptive \\
\hline Litis & Study (Persian)]. Archives of Rehabilitation. 2019; 20(1):16-27. http://dx.doi.org/10.32598/rj.20.1.16 \\
\hline loter & doil $h t$ ttp://dx.doi.org/10.32598/rj.20.1.16 \\
\hline
\end{tabular}

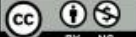

Received: 10 Nov 2018 Accepted: 20 Feb 2019 Available Online: 01 Apr 2019

Keywords:

Family-centered approach, Measurement of care process, Service providers

\begin{abstract}
Objective Family is the center and core of the patient's care, so the most effective therapeutic programs are those that emphasize the role of the family in treatment. The purpose of this study was to evaluate the delivery of family-centered services by service providers for families and children in Iran based on the Persian version of the Measure of Processes of Care for Service Providers (MPOC-SP) Questionnaire. Materials \& Methods In this study, 150 service providers participated including doctors, nurses, midwives, rehabilitation therapists, as well as graduates in public health. The Persian version of the MPOC-SP questionnaire was used to collect the study information. The collected data were then analyzed in SPSS 22.

Results The results showed no significant difference between men and women providing the service regarding the components of the questionnaire for measuring the process of care. The mean of components in "providing general information" in the medical group was statistically significant and higher compared to the basic science group. The average score of "showing interpersonal sensitivity", "providing general information", and mean score of total services in different service centers were statistically significant. The average score of the "showing interpersonal sensitivity", "providing of general information" as well as the mean score of the whole questionnaire of the process of care in the private centers was statistically significant and higher than the governmental centers. The average components of "showing interpersonal sensitivity", "treating people respectfully", "providing of general information", as well as the average score of the total questionnaire of the process of care in different age groups of service recipients were statistically significant. The average of the same components in different service providers also had a statistically significant difference.

Conclusion providers' responses showed that health and rehabilitation centers provided good services in terms of respectful behavior, but providing general information and showing interpersonal sensitivity were relatively weak areas. The average scores of these components as well as the average total score of the questionnaire were the highest in rehabilitation fields and then ranked by medical and other therapy personnel respectively.
\end{abstract}

\section{* Corresponding Author:}

Azade Riyahi, MSc.

Address: Department of Occupational Therapy, School of Rehabilitation, Arak University of Medical Sciences, Arak, Iran.

Tel: +98 (86) 34173502

E-Mail: azade.riyahi@yahoo.com 


\title{
بررسى نحوه ارائه خدمات خانوادهمحور توسط كادر بزشكى و توانبخشى: يك مطالعه توصيفى
}

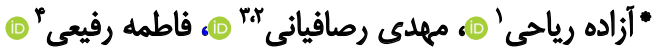

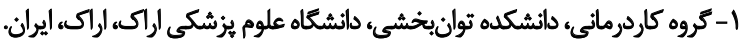

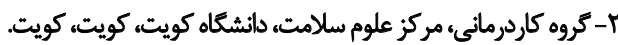

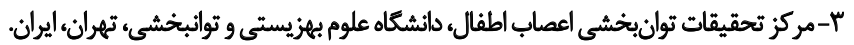

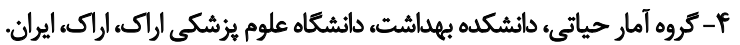

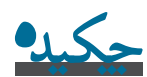

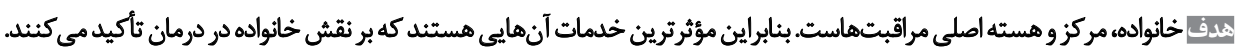

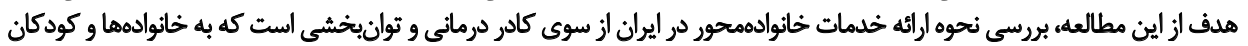
خدمات إرائه مي كنيند.

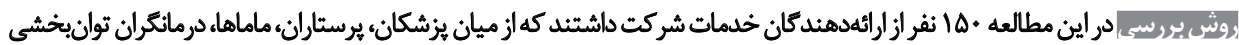

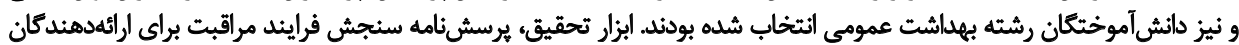

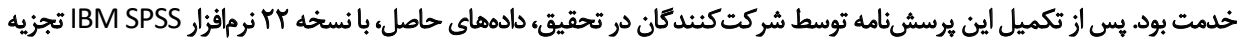
و وتحليل شد.

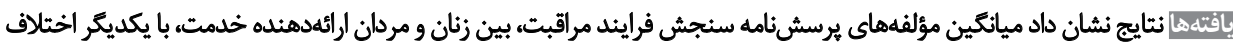

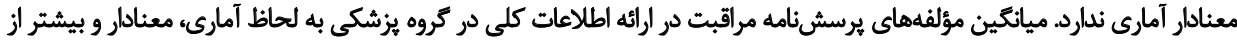

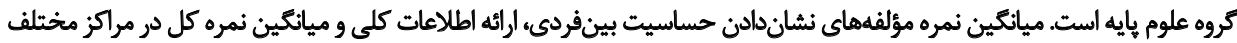

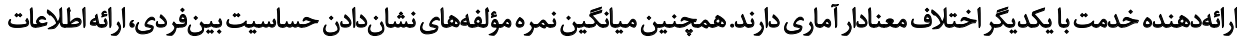

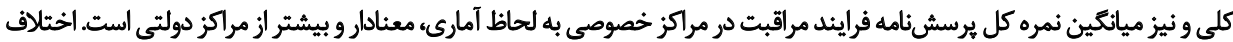

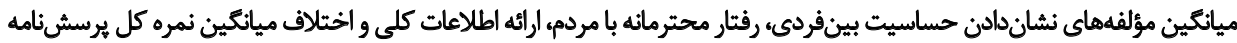

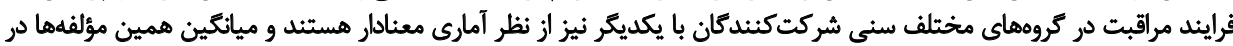

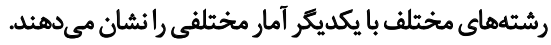

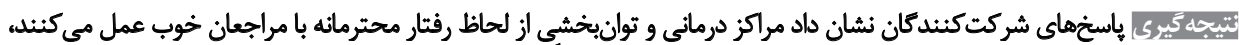

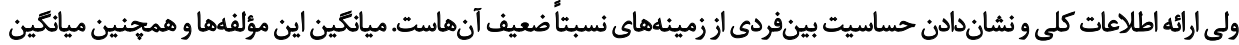

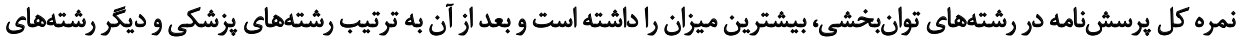

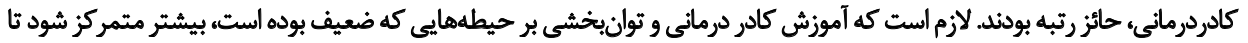

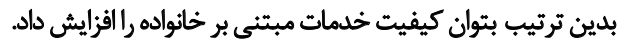

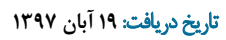

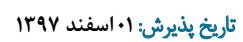

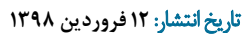

كليدواثرهها:

رويكرد خانوادهمحور، سنجش فرايند مراقبت،

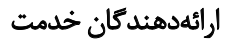

معرفى و مورد استفاده قراركرفت [Y]]. در اين رويكرد، به جائ

dalos

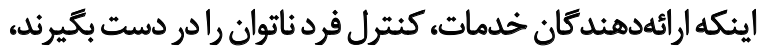

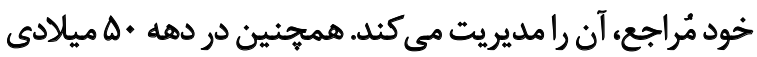

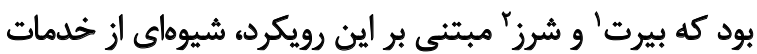

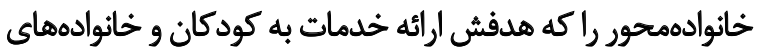

1. Bert

2. Sherz

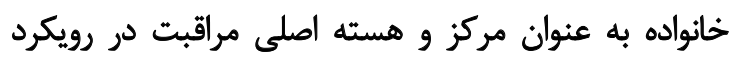

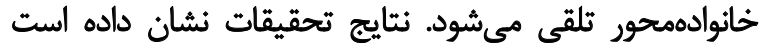

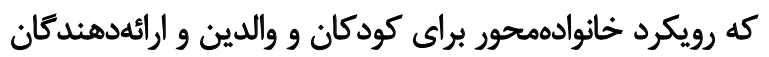

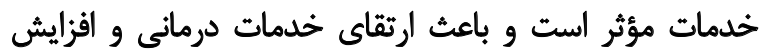

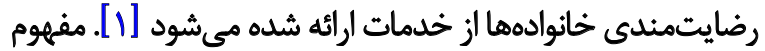

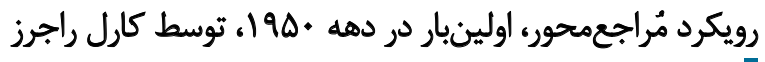

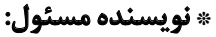
آزاده وياحى نوينده تشانى: اراك، دانشكاه علوم يزشُكى اراك، دانشكده توانبخشى، كروه كاردرمانى.

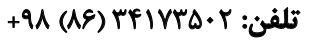
رايانامه: azade.riyahi@yahoo.com 
بهداشت و سيستم آموزشى در ايران وجود ندارد.

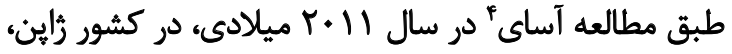

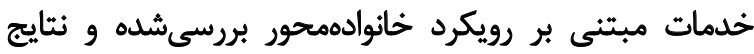

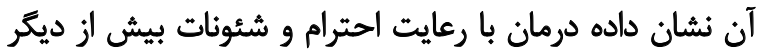

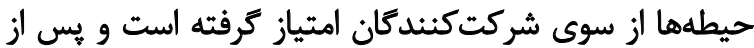

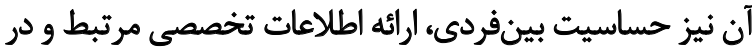

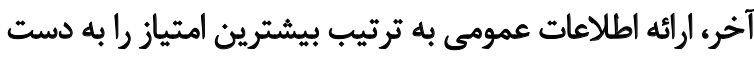

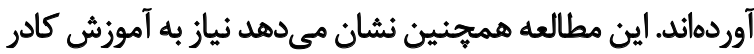

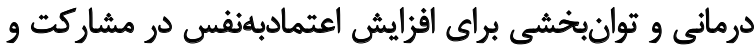

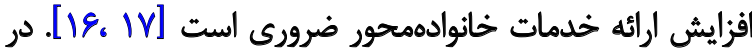

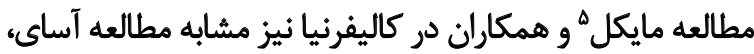

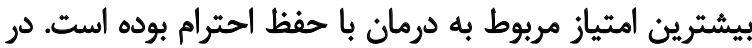

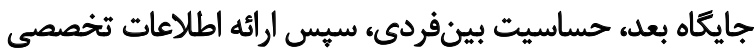

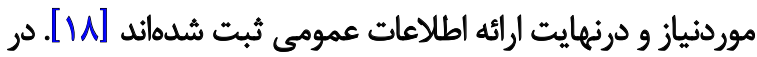

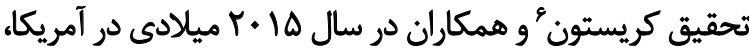

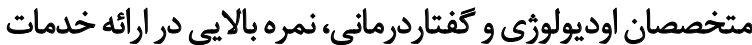

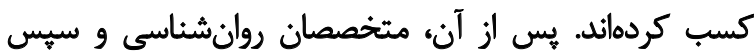

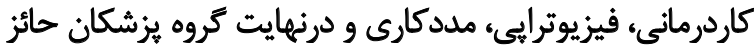

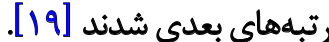

نظر به اينكه تا كنون مطالعهاي درباره ابعاد مختلف نحوه ارائه

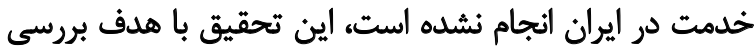

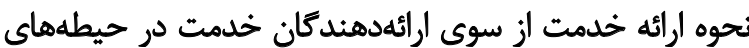

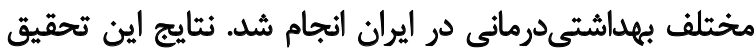

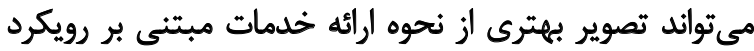

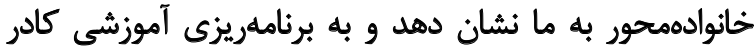

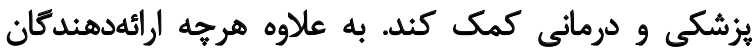

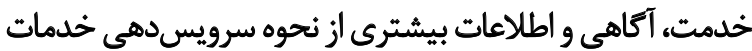

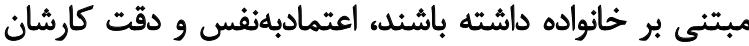

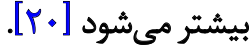

$$
\text { روش بروسى }
$$

مطالعهاى به صورت مقطعى در شهر اراك درباره مسئله

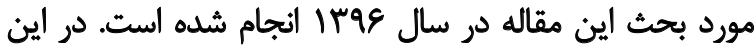

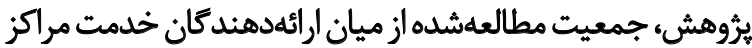

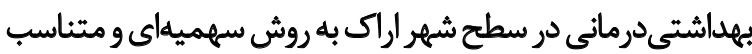

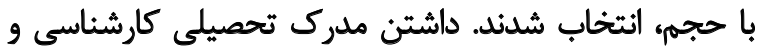

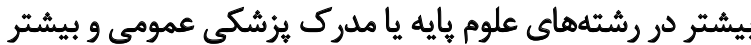

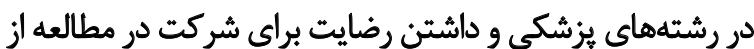

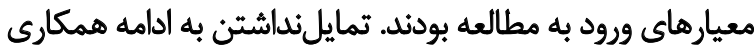

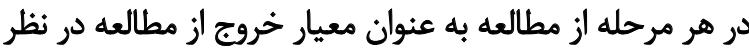

4. Asai

5. Michelle

6. Christon
[آنها بود، ارائه كردند [ب]

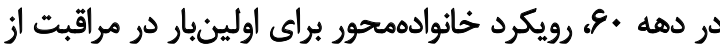

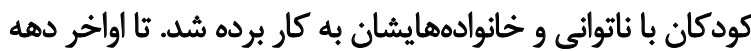

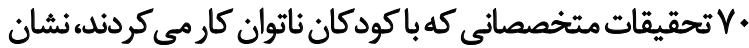

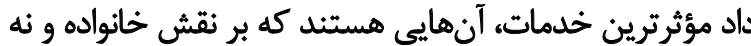

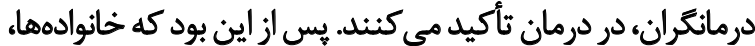

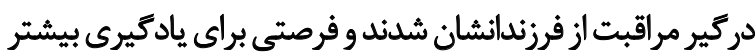

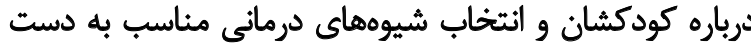

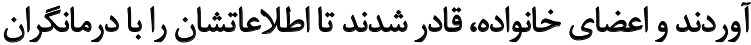

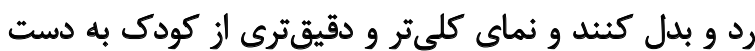

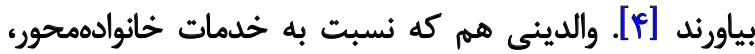

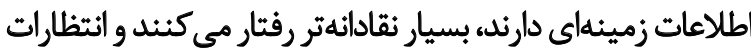

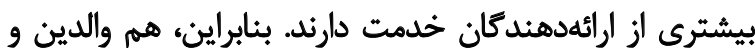

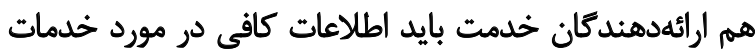

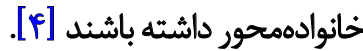
از آنجا كه مشاركت اعضاى خانواده در مراقبت از كودك، يكى ازئ

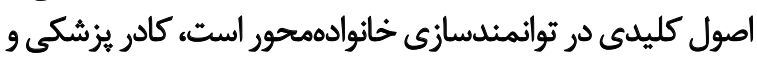

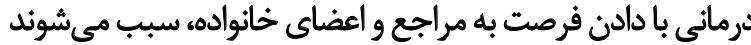

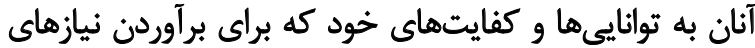

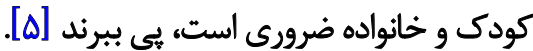
از ديدكاه مركز تحقيقاتى كن خايلدّ، خدمات خانوادهمحورو،

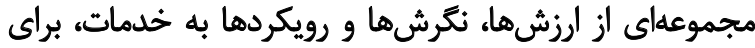

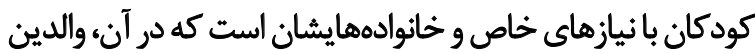

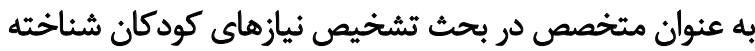

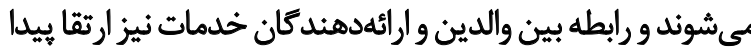

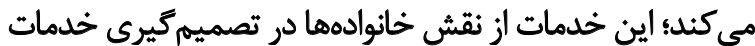

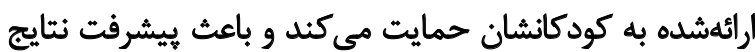

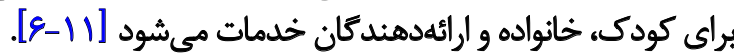
كيمارىهاى مزمن و ناتوانى كودكى، اثرات درخور توجهى در

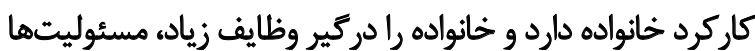

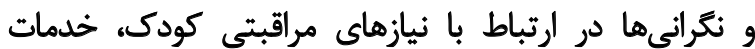

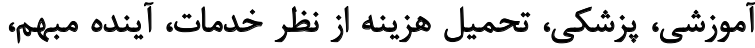

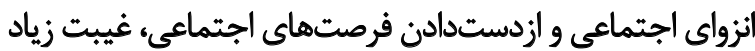

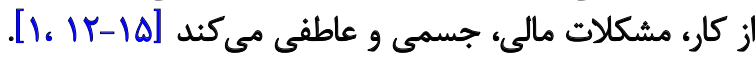

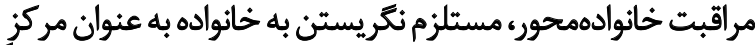

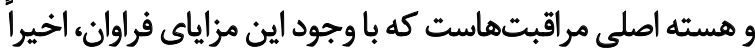

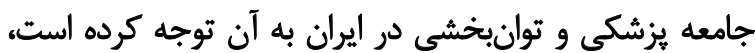

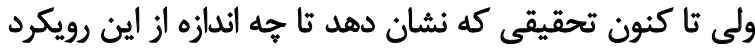

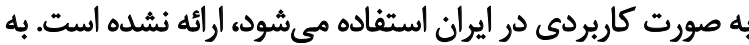

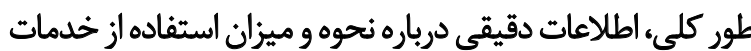

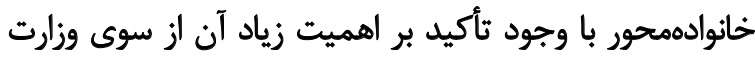

3. Can Child Centre for Childhood Disability Research 


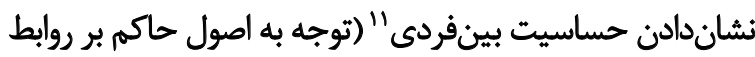

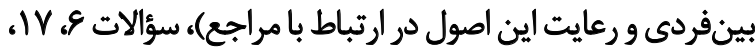

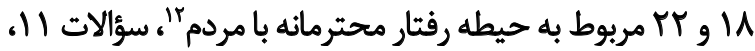

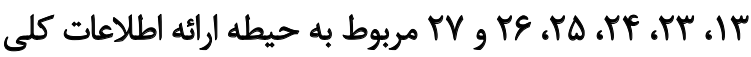

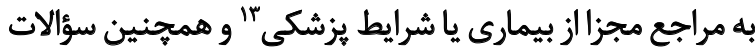

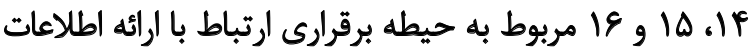

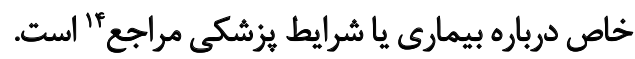
بر اساس مطالعه رياحى و همكاران، نسخه فارسى يرسش نامنه

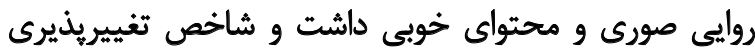

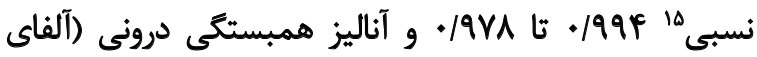

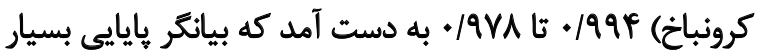
مطلوب نسخه فارسى بود. همجناء (9AV)

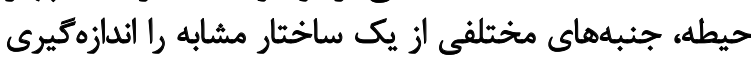
مى كند.

bevill

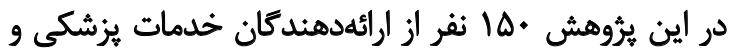

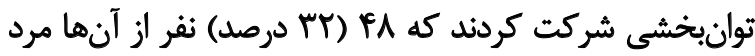

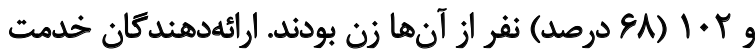

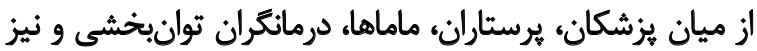

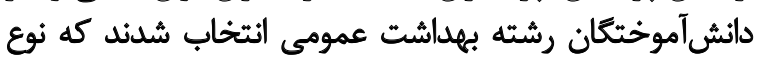

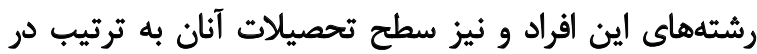
جدول شماره آمده است.

كمترين سن شركت كنيندان، إل سال و بيشترين سن نيز

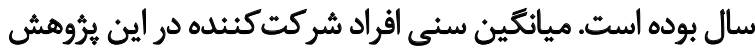

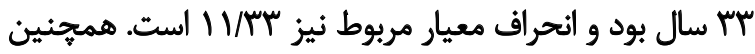

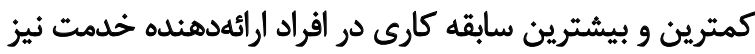

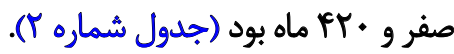
19 نفر (r/ ه د درصد) از شركت كنند

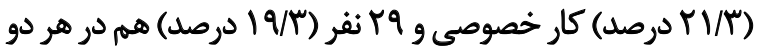

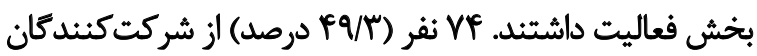

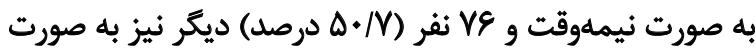

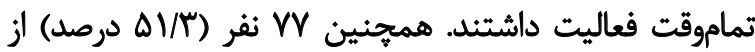

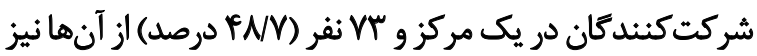

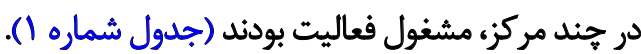

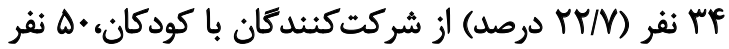

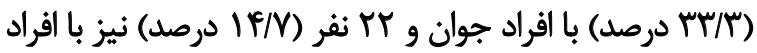

11. Showing Interpersonal Sensitivity

12. Treating people respectfully

13. Providing general information

14. Communicating specific information

15. Intra class Correlation Coefficient (ICC)
كرفتّه شُ.

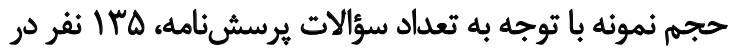

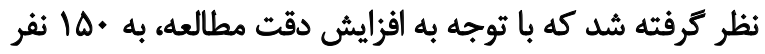

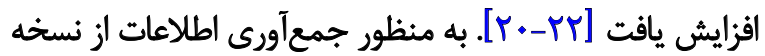

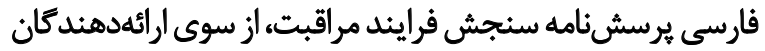

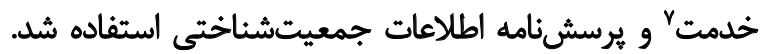

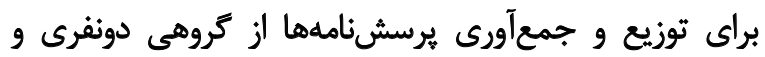

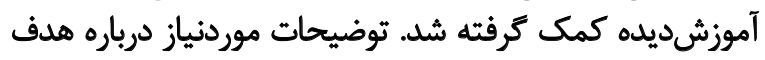

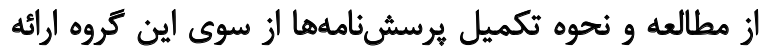

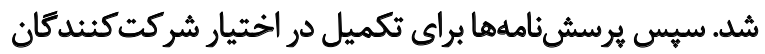

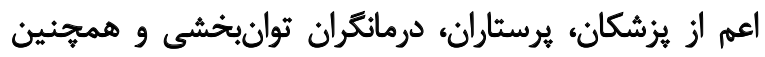

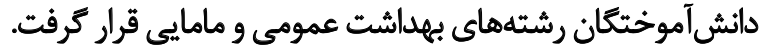

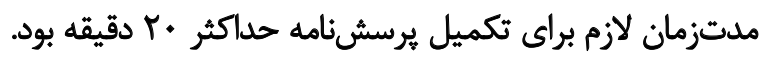

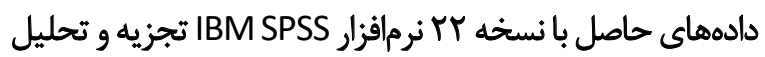

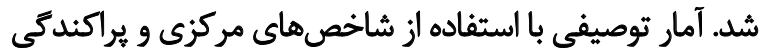

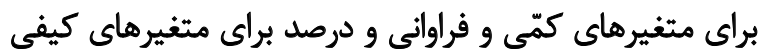

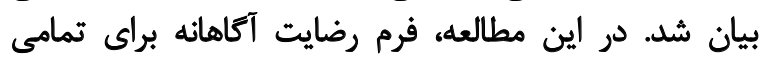

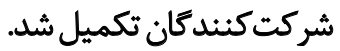

أبوال بثووهش

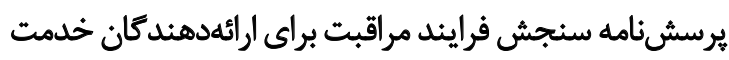

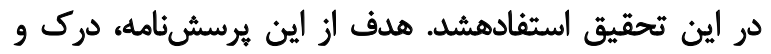

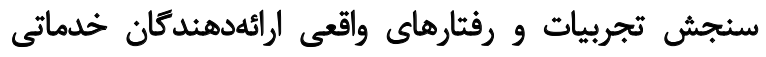

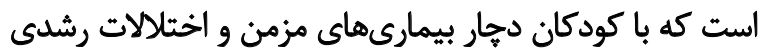

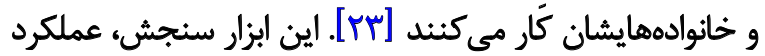

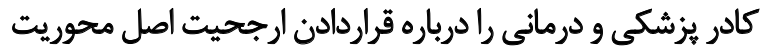

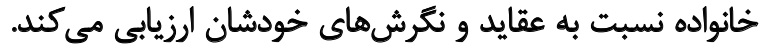

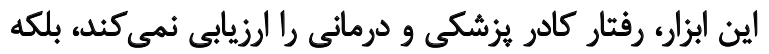

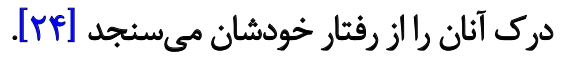

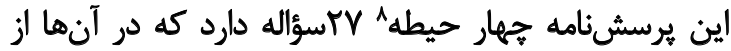

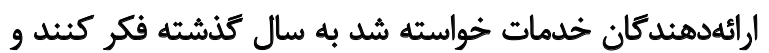

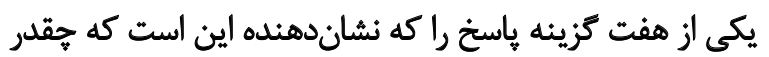

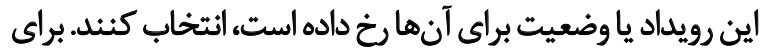

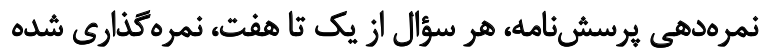

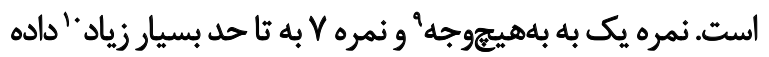

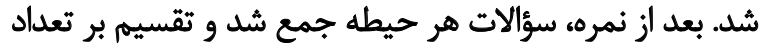

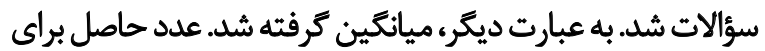

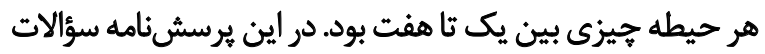

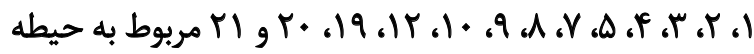

7. Measure of Processes of Care for Service Providers (MPOC-SP)

8. Domain

9. Not all

10. A very great extent 
جدول ا. اطلاعات جمعيتشنئاختى مربوط به شركت كنئدكان در مطالعه

\begin{tabular}{|c|c|c|c|}
\hline تروصد & فراوائى & آيتمها & مثغيرها \\
\hline $11 / r$ & iv & يرستار & \\
\hline$N Y$ & ir & ماما & \\
\hline $\mathrm{v} / \mathrm{l}$ & 18 & كاردرمانكر & \\
\hline$T / M$ & r & كفتاردرمانكر & رشتئه تحصيلي \\
\hline$V / r$ & 11 & بهداشت عمومى & \\
\hline$\Delta q / \mu$ & 19 & يزئشى & \\
\hline $1 .$. & 10. & كل & \\
\hline$r$ & $\Delta$ & كارششاس & \\
\hline r & r & كارشناس ارشد & \\
\hline $1 / \pi$ & $r$ & دكترا و بالاتر & \\
\hline m & pq & يزشك عمومى & \\
\hline$V / r$ & 11 & دانشجوى تخصص & سطح تحصيلات \\
\hline in & iv & متخصص & \\
\hline.$/ V$ & 1 & دانشجوى قوقتخصص & \\
\hline$T / Y$ & $f$ & فوقتخصص & \\
\hline $1 .$. & 10. & كل & \\
\hline$\Delta q / r$ & 19 & كولثى & \\
\hline$r M / r$ & $\pi$ & خُصوصى & نوع محل كار \\
\hline $19 / \pi$ & $p q$ & دولتى و خصوصى & \\
\hline $1+*$ & $10+$ & كل & \\
\hline$p q /{ }^{\prime \prime}$ & $n$ & نيمهوقت & \\
\hline$\Delta \cdot / N$ & ve & تماموقت & مدت زمان كار \\
\hline 1.0 & 10. & كل & \\
\hline$\Delta V / \Gamma$ & $w$ & يك مركز & \\
\hline PNY & $n^{m}$ & جند هركز & تعلداد مراكزى مشغول به كار \\
\hline 1.0 & 10. & كل & \\
\hline$r T / Y$ & $\pi$ & كودكان & \\
\hline$\pi / \pi$ & Q. & 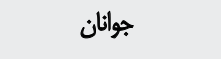 & \\
\hline $\mid f / Y$ & Mr & 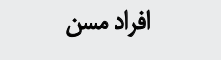 & كروه سنى بيماران تحت درمان \\
\hline$r q / \mu$ & if & تمامى كروهالى سنى & \\
\hline $1 .$. & 10. & كل & \\
\hline
\end{tabular}

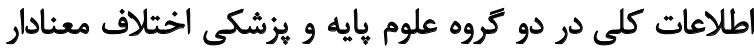

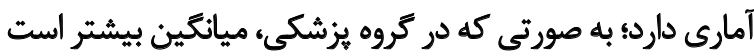

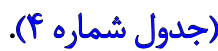
ضمناً نثايج آزمون كروكسال واليس نشان داد داد ميانكين نمره

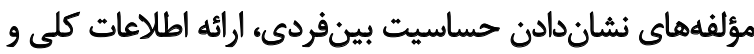

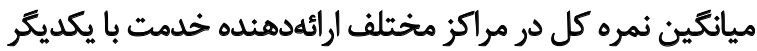

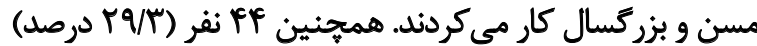

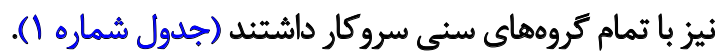

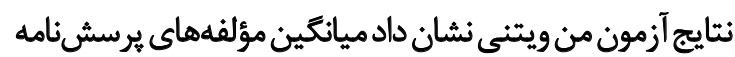

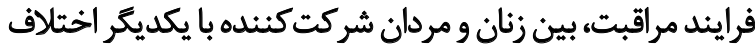

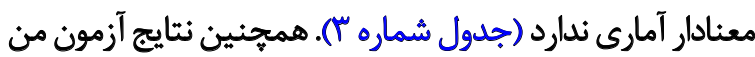

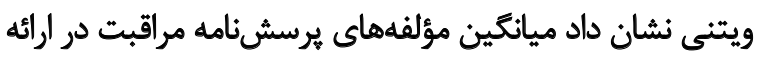


جدول r. مربوط به سن و سابقه كار شركت كنيدكان

\begin{tabular}{|c|c|c|c|c|c|}
\hline انحراف معيار & مياتكين & بيشترين & كمترين & تعداد & متغيرها \\
\hline $1 \mathrm{~W} / \mathrm{r}$ & "זr & 9 & $r$ & 10. & سن \\
\hline $1.1 / N$ & $11+1+r$ & Pr. & . & 10. & سابقه كار \\
\hline
\end{tabular}

جدول r. مقايسه ميانكين و انحراف معيار مؤلفههاى برسشنامه فرايند مراقبت در دو تروه زنان و مردان شركتكندكان

\begin{tabular}{|c|c|c|c|c|c|c|}
\hline \multicolumn{2}{|c|}{ أزمون من ويتثي } & \multicolumn{2}{|c|}{ زن } & \multicolumn{2}{|c|}{ مررد } & \multirow{2}{*}{ متغيرها } \\
\hline $\mathbf{P}$ & آماره & انحراف معيار & مياتكين & انحراف معيار & مياتكين & \\
\hline . Iva & TrAF/A & /ar & FNG & .191 & F/AT & نشاندادن حساسيت بينفردى \\
\hline .1 .94 & r.rV/Q & l/s & $\Delta / \pi r$ & .188 & $\Delta / \Delta 9$ & رفتار محتر مائه با مردم \\
\hline.$/ 90 T$ & mert & $1 / 19$ & $F / N$ & +/q1Y & $F / A$ & ارائه اطالاعات كلى \\
\hline .1059 & $M \cdot V / \Delta$ & $\mathrm{V} / \mathrm{V}$ & $r a / / r$ &.$/ Q \varepsilon$ & $ه / 11$ & برقرارى ارتباط با ارائه اطلاعات خاص \\
\hline - lgat & $m+1 \Delta$ &.$/ 9 \Delta$ & F/AV &.$/ \Delta A$ & p/ar & ميانكين نمره كل \\
\hline
\end{tabular}

توانبخننى

نتايج آزمون مقايسه زوجى نشان داد ميانكين مؤلفههاي

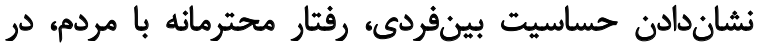

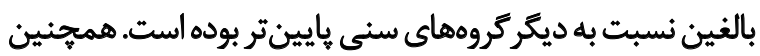

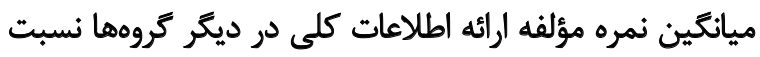

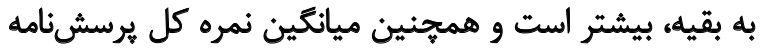

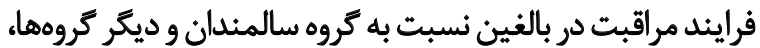

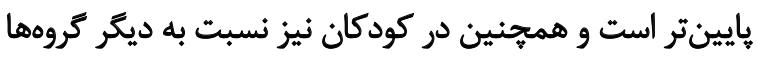
يايينتر است (جدول شمارهم).

نتايج آزمون كروكسال واليس نشان داد ميانكين مؤلفههاى

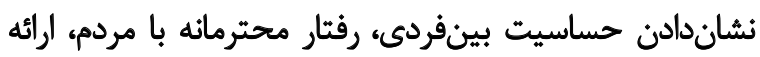

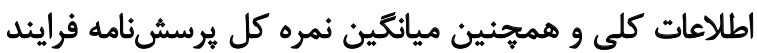

اختلاف معنادار آمارى دارد (جدول شماره ه). نتايج آزمون مقايسه زوجى نشان داد ميانكين نمره

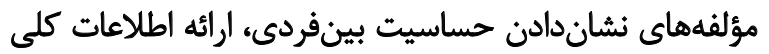

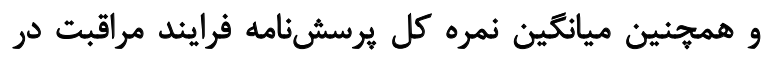

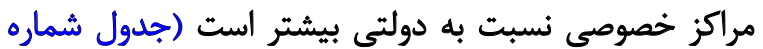

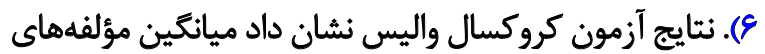

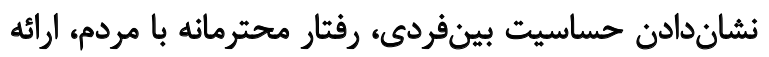

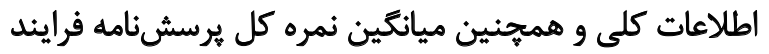

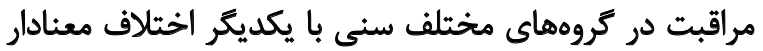
آمارى دارد (جدول شماره مرون).

جدول f. مقايسه ميانكين و انحراف معيار مؤلفههاى هيرسشنامه فرايند مراقبت در دو كروه علوم هايه و يزشكى ارائهدهنده خدمت

\begin{tabular}{|c|c|c|c|c|c|c|}
\hline \multicolumn{2}{|c|}{ أزمون من ويتنى } & \multicolumn{2}{|c|}{ يزشكى } & \multicolumn{2}{|c|}{ علوم خايه } & \multirow{2}{*}{ متغيرها } \\
\hline $\mathbf{P}$ & آماره & انحراف معيار & مياتكين & انحراف معيار & مياتكين & \\
\hline.$/ 4 \cdot 9$ & requ/a &.$/ 81$ & P/AY & $1 / \cdot$ & r/ge & نشاندادن حساسيت بينفردى \\
\hline.$/ T 19$ & THNA & $+|A|$ & $\Delta / F \Delta$ & $1 / r$ & $\Delta / r$ & رفتار محترعائه با مردم \\
\hline $.1 \cdot \pi$ & rire/o & . & $r / u$ & $1 / r$ & $p / q q$ & ارائه اطلاعات كلى \\
\hline.$/ M A$ & TETV/A & - IAV & $\Delta / r_{0}$ & $1 / r$ & $\Delta / \cdot r$ & برقرارى ارتباط با اراثيه الطلاعات خاص \\
\hline.$N \& V$ & Trar/a & .181 & $\Delta / \bullet r$ & $v \cdot r$ & $F / M$ & ميانكين نمره كل \\
\hline
\end{tabular}


جدول هـ. مقايسه ميانكين و انحراف معيار مؤلفهاي برسشنامه فرايثد مراقبت بر اساس نوع مراكز ارائهدهنده خدمت

\begin{tabular}{|c|c|c|c|c|c|c|c|c|}
\hline \multicolumn{2}{|c|}{ آزمون كروكسال واليس } & \multicolumn{2}{|c|}{ 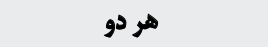 } & \multicolumn{2}{|c|}{ خصوصى } & \multicolumn{2}{|c|}{ 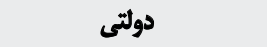 } & \multirow{2}{*}{ متغيرها } \\
\hline $\mathbf{P}$ & $\mathbf{F}$ & انحراف معيار & مياتكين & انحراف معيار & مياتكين & انحراف معيار & مياتغين & \\
\hline .1 .11 & $9 \cdot 50$ & $\cdot M$ & $\Delta /+\varphi$ & . NO & $\Delta / \cdot r$ & $\cdot \mid N$ & $r / 81$ & نشاندادن حساسيت بينفردى \\
\hline $.1 . v 8$ & $\Delta / \backslash \Delta q$ &.$/ N$ & $\Delta / \Delta q$ &.$M$ & $\Delta / \Delta q$ & $v \cdot r$ & $\Delta / / 9$ & رقفتار محترمانه با مردم \\
\hline.$/ . r 1$ & VIFqu & $1 / \varphi$ & $\Delta / \div A$ & .119 & $\Delta / \cdot 9$ & $1 / 10$ & r/OV & ارارأه اطلاعات كلى \\
\hline . IEW &.$/ V A 1$ & $1 / 9$ & $\Delta / r$ & V.r & $\Delta / \pi$ & $1 / 10$ & $\Delta / .9$ & برقرارى ارتباط با ارائه اطلاعات خاص \\
\hline$\%$ & $V / \& \cdot Y$ &.$/ M^{e}$ & $\Delta / 1 \Delta$ &.$M A$ & $\Delta / 10$ & IAYY & eMr & ميانكين نمره كل \\
\hline
\end{tabular}

جدول \&. نتايج آزمون مقايسه زوجى ميانكين مولفه هاى مراقبت در كروه ها

\begin{tabular}{|c|c|c|c|}
\hline معنى دارى & كروه (J) & تروه (I) & متغيرها \\
\hline $\begin{array}{l}. / 014 \\
. / * r \mid\end{array}$ & هُصوصى هردو & دولتى & نشان دادن حساسيت بين فردى \\
\hline $\begin{array}{l}.1 .47 \\
.1014\end{array}$ & هصوصى & 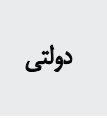 & الرائه ى اطلاعات كلى \\
\hline $\begin{array}{l}.1 .4 F \\
.4 \% g\end{array}$ & خصوصى & 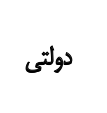 & ميانكين نمره كل \\
\hline
\end{tabular}

مراقبت در رشتهاى مختلف ارائهدهنده خدمت با يكديكر بحث هدف اصلى از اين مطالعه، بررسى ارائه خدمات خانوادهمحور

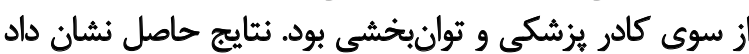

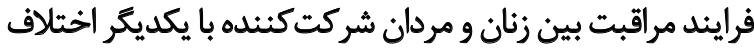

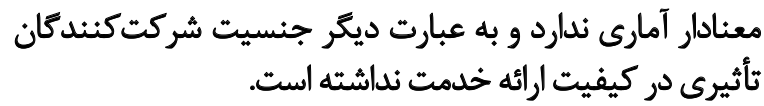

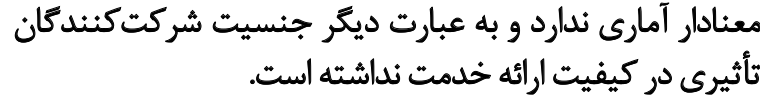

اختلاف معنادار آمارى دارد (جدول شماره 9 9). درباره تأثير ميزان سابقه كار شركتكنندكان بر نحوه ارائه

در نتايج مطالعه درباره امتياز حيطههاى مختلف يرسشنامهامه

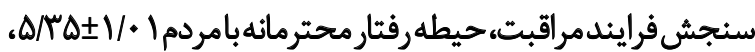

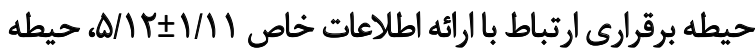

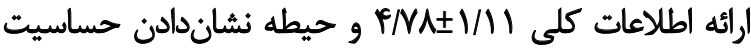

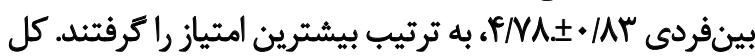

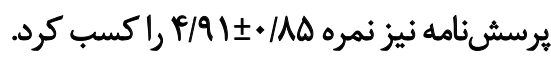

جدول V. مقايسه ميانكين و ائحراف معيار مؤلفههاى برسش نامه فرايند مراقبت بر اساس كروههاى مختلف سنى دريافت كنيده خدمت

\begin{tabular}{|c|c|c|c|c|c|c|c|c|c|c|}
\hline \multicolumn{2}{|c|}{ أزمون كروكسال واليس } & \multicolumn{2}{|c|}{ تمامى كروهها } & \multicolumn{2}{|c|}{ 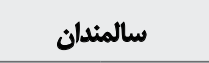 } & \multicolumn{2}{|c|}{ يزرئسالان } & \multicolumn{2}{|c|}{ كودكان } & \multirow[b]{2}{*}{ متغيرها } \\
\hline $\mathbf{P}$ & $\mathbf{F}$ & انحراف & مياتكين & انحراف & مياتكين & اتحراف & مياتئين & انحراف & مياتئين & \\
\hline$* \ldots+1$ & WAYG & $.19 V$ & $\Delta / I T$ & - IAF & $e / u$ & .19 & $r / 2 q$ &.$/ Y$ & $E / W$ & تشاندادن حساسيت يينفردى \\
\hline $.1 .+1$ & $r \Delta / r+9$ &.$/ 94$ & $\Delta / A)$ & $\cdot / V$ & ANV & $m$ & r/ar &.$/ 99$ & $ه / 11$ & رفتار محترماثه با مردم \\
\hline $.10+r$ & $|F / A| A$ & $\cdot M$ & $\Delta / r$ & $1 / * 1$ & P/AS & 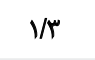 & $r / m$ &.$/ 9$ & $P / \Delta V$ & ارإيه اطلاعات كلى \\
\hline . Mat & PlNes &.$/ 9 \Delta$ & $\Delta / \tau \Lambda$ & V.r & $\Delta / P 1$ & WTY & $\Delta / \cdot 1$ & $1 / \cdot \Delta$ & $P / M$ & برقرارى ارتباط با الرائه اطلاعات خاص \\
\hline$+1++\infty 1$ & $W A+\Delta$ & 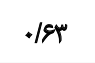 & $\Delta / 7 q$ & $+|A|$ & $\Delta / 11$ & .198 & $F / \Delta \Delta$ & $\cdot / N$ & $F / W$ & ميائكين نمره كل \\
\hline
\end{tabular}


جدول A. نتايج آزمون مقايسه زوجى ميائكين مؤلفههاى مراقبت در گروههاي مختلف سنى

\begin{tabular}{|c|c|c|c|}
\hline معنى مارى & (J) & (I) & متغيرها \\
\hline$\% \% q$ & كودكان & \multirow{3}{*}{ بالغين } & \multirow{3}{*}{ نشاندادن حساسيت بينفردى } \\
\hline .1 .10 & سالمندان & & \\
\hline $.1+. .1$ & هoهo & & \\
\hline .1 .0 & كودكان & \multirow{3}{*}{ بالغين } & \multirow{3}{*}{ رفتار محتر مانه با مردم } \\
\hline 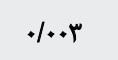 & سالمنلان & & \\
\hline $.1+\ldots 1$ & هos & & \\
\hline .10 .4 & كودكان & \multirow{3}{*}{$\operatorname{los}_{\log }$} & \multirow{3}{*}{ اراثيه اطلاعات كلى } \\
\hline .1 .01 & بالغين & & \\
\hline$\%+P Y$ & سالمنلان & & \\
\hline .1 .48 & سالمندان & \multirow{2}{*}{ بالغين } & \multirow{3}{*}{ ميانكين ثمره كل } \\
\hline $.1 . . .1$ & همه كروهها & & \\
\hline $.1 . . r$ & كودكان & همله كروهـا & \\
\hline
\end{tabular}

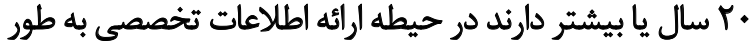

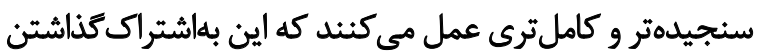

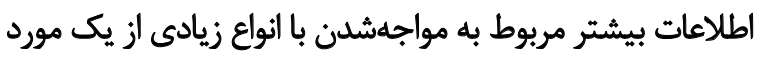

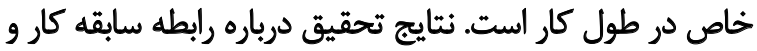

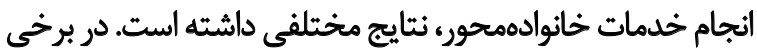

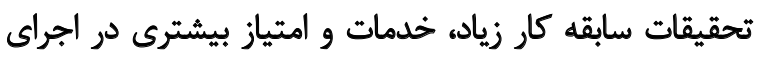

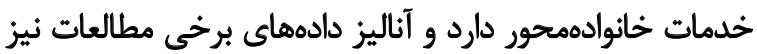

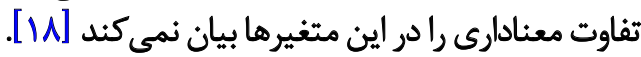

نتايج حاصل از اين تحقيق همجنين نشان داد مؤلفههاى مراقبت

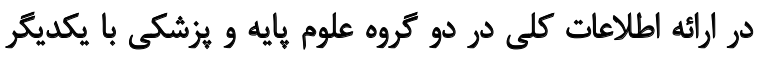

خدمت، همبسئكي مثيتي بين سابقه كار اين افراد بر نحوه ارائه

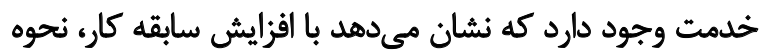
الرائه خدمت نيز ارتنقا مي فيابد. مطالعه مايكل و همكاران در سال V • . . ميلادى در كاليفرنيانيز

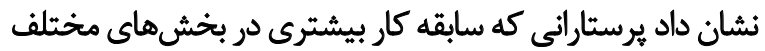

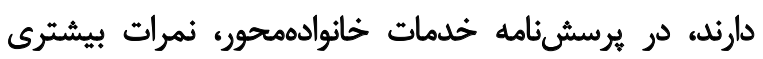

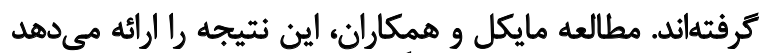

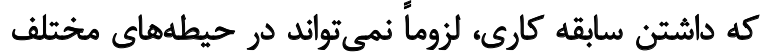

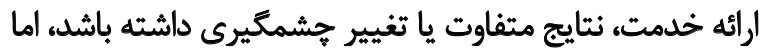

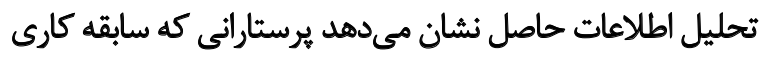

جدول 9.

\begin{tabular}{|c|c|c|c|c|c|c|c|c|c|c|c|c|c|c|}
\hline \multicolumn{2}{|c|}{ أزمون كروكسال } & \multicolumn{2}{|c|}{ برثشكى } & \multicolumn{2}{|c|}{ بهداشت عمومى } & \multicolumn{2}{|c|}{ كفثتاردرمائمى } & \multicolumn{2}{|c|}{ كارقرماتى } & \multicolumn{2}{|c|}{ مامايي } & \multicolumn{2}{|c|}{ هبرستارى } & \multirow{2}{*}{ متغيرها } \\
\hline $\mathbf{P}$ & أماره & اتحراف & ميلكين & اتحراف & ميلكين & أحعراف & ميلكين & اتحراف & ميلكين & اتحراف & ميلكين & اتحراف & ميلتكين & \\
\hline $.1 \ldots .+1$ & $r \Delta / \Delta M^{\prime \prime}$ &.$/ 8 A$ & $P / A V$ & $\cdot|A|$ & P/OT & .18 & $\Delta / \Delta q$ & $.18 \Delta$ & $\Delta / m f$ & $M$ & P/IT & $M^{\circ}$ & $P / T q$ & نشاندانيت \\
\hline$\% \Delta$ & $18 / 9 \cdot \gamma$ & $\cdot|A|$ & $\Delta / \mp \Delta$ & I/Tq & $r /(1)$ &.$/ 91$ & 8 & $.18 \lambda$ & $\Delta / 9 \Delta$ & $1 / 8$ & $F / 9$ & $M$ & $F / A r$ & رفتار محترمانه \\
\hline$* / * 1 \gamma$ & IT/ATQ & $+/ 94$ & $r / u$ & $+/ Y$ & $r / W$ & $1 / 19$ & $\Delta / T T$ & $+/ 9 F$ & $\mathrm{~F} / \mathrm{U}$ & $V / \Delta S$ & $r / \%$ & $1 / 5$ & $F /+r$ & ارارائه اطلاليات \\
\hline ./en & P/AT. & $\cdot / A V$ & $\Delta / r$ & $1 / 4$ & $\Delta$ & - $M A$ & $\Delta / 91$ & V/Tr & $\Delta / \cdot T$ & $1 / 4$ & $\Delta / / V$ & V/P & $P / N$ & 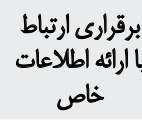 \\
\hline .1 .01 & $r \cdot / F \Delta \mid$ & . I\&A & $a / \circ r$ & . Ar & Y/EA & 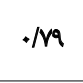 & Q/Fr & $\cdot M$ & $\Delta / r$. & $1 / \pi$ & $T / \pi$ &.$/ 9 F$ & E/Ta & ميانكين نهره \\
\hline
\end{tabular}


كودكان با سنين بيشتر درك مى كنيند. همجينين ديكر مطالعات،

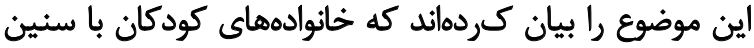

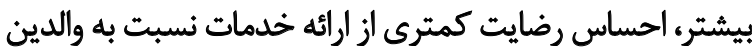

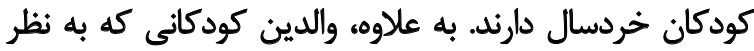

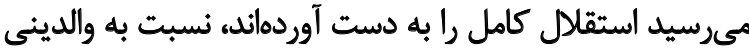

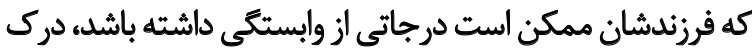

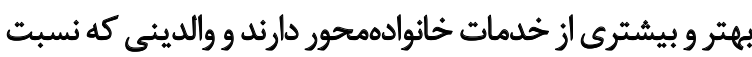

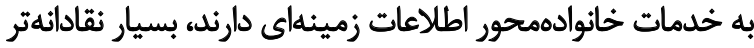

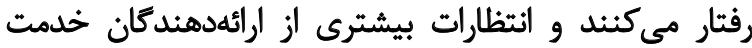

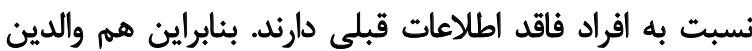

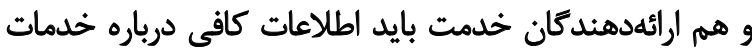

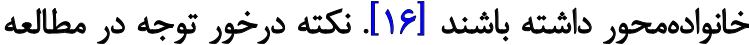

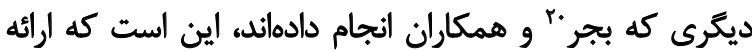

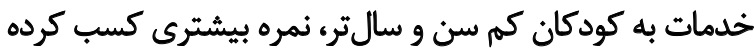

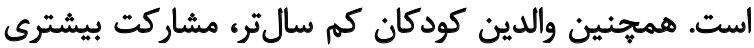

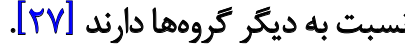

نتايج اين مطالعه درباره امتياز حيطههاي مختلف يرسشنامه

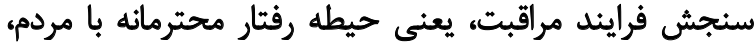

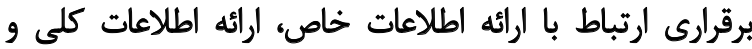

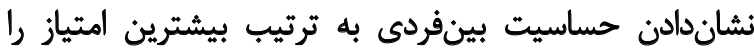

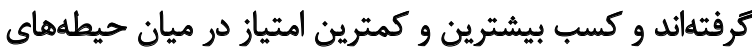

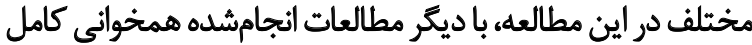

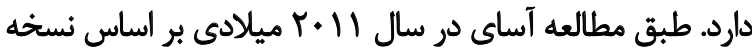

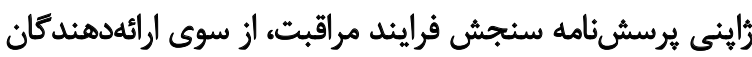

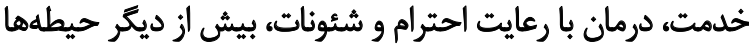

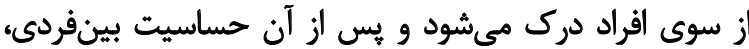

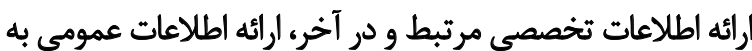

ترتيب بيشترين امتياز راكرفتها|ند. [IV]

در مطالعه مايكل و همكاران نيز مشابه مطالعه آساى، در

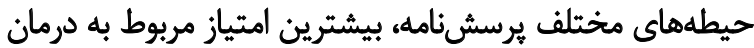

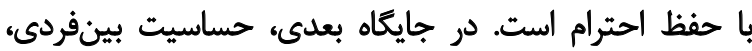

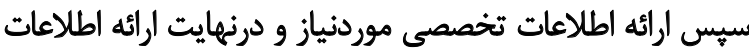

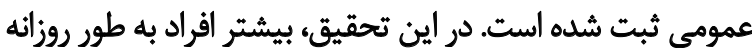

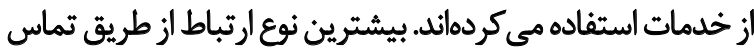

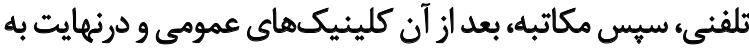

صورت ويزيت در منزل بوده است [1/1]].

\section{نتيجهاكيّرى}

نتايج اين مطالعه نشان داد مراكز درمانى و توانبخشى از

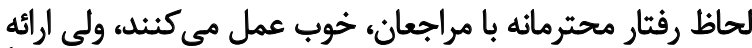

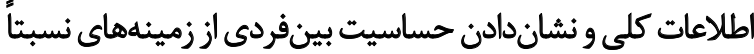
ضعيفشان بوده است. همجينين ميانكين اين مؤلفهها و ميانكين

20. Bjerre
اختلاف معنادار آمارى داردو ودر كروه يزشككى بيشتر است. نثايج اين

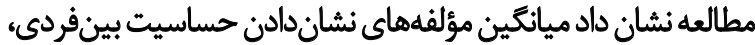

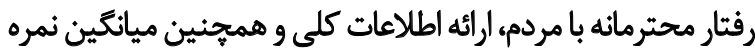

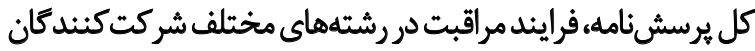

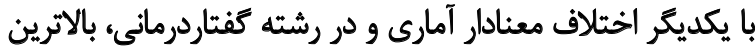

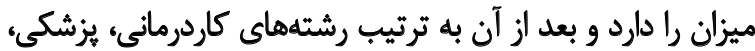

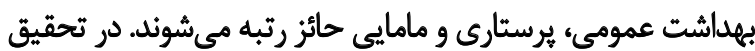

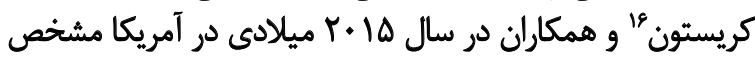

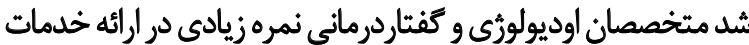

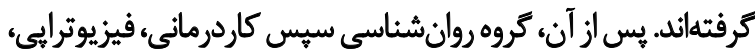

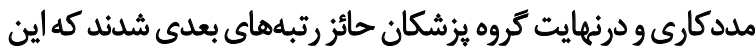

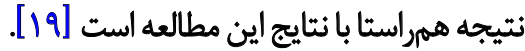

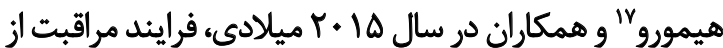
سوى ارائهدهندكان خدمات براي تيمهاي هائ جندر

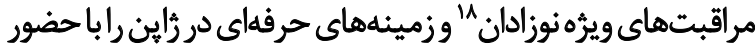

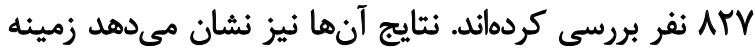

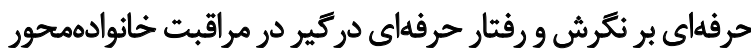

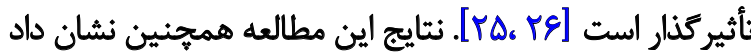

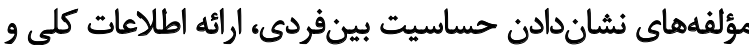

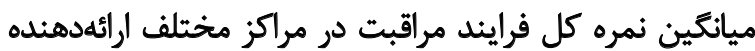

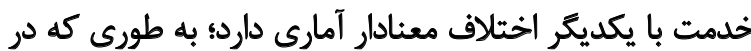

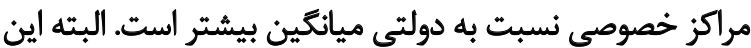

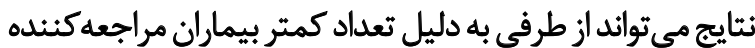

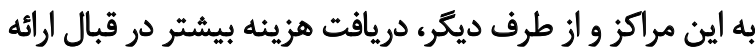
خدمات، نسبت به مراكز دولتى باشد.

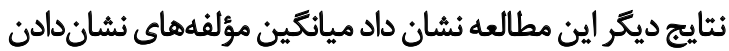

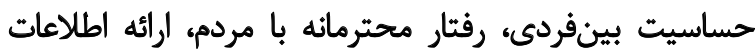

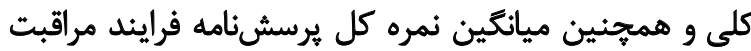

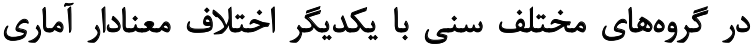

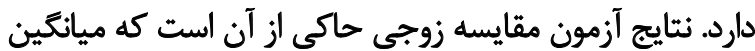

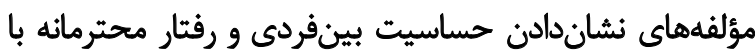

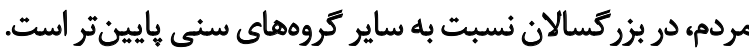

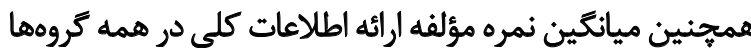

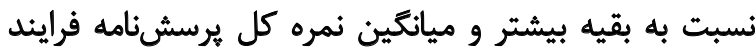

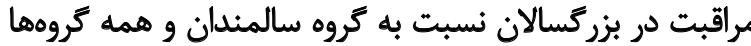

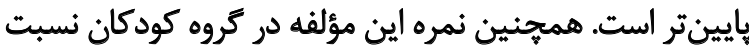
به همه تروهها بايينتر ارزيابي شده است.

مطالعه استفانسدوتير" و ومكاران، در اسكانديناوي نشان داده است والدين كودكان با سن كمتر، خدمات را بهتر از والدين

\section{Christon}

17. Himuro

18. Neonatal Intensive Care Unit (NICU)

19. Stefánsdóttir S 
نمره كل يرسشنامه در رشتهاي توانبخشى بيشترين ميزان را راني

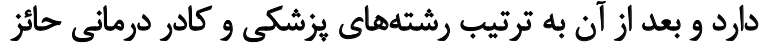

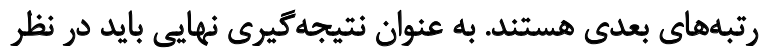

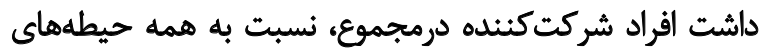

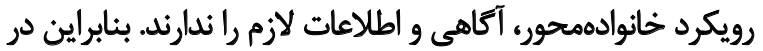

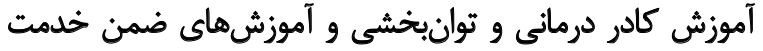

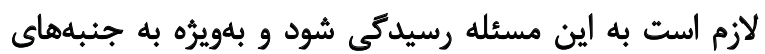
ضعيف اين رويكرد، اهميت بيشترى داده شود.

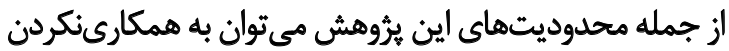

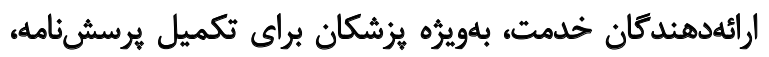

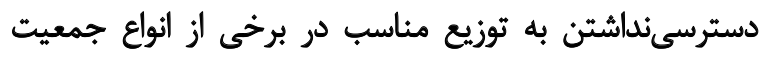

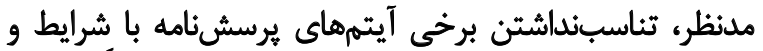

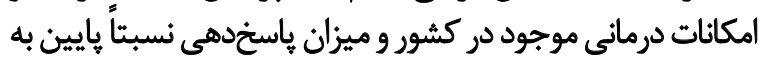

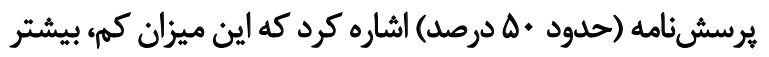

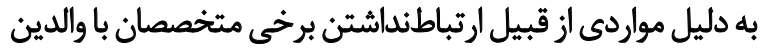

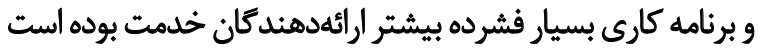

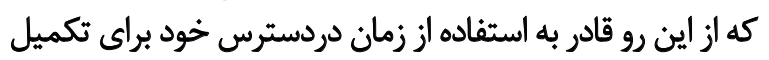
يرسشنامهنبودهاند.

در بايان، بيشنهاد ميشود مطالعاتى با هدف بررسي نحوه ارائه

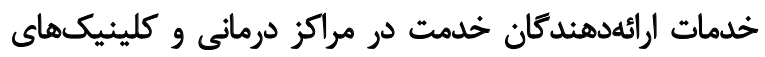

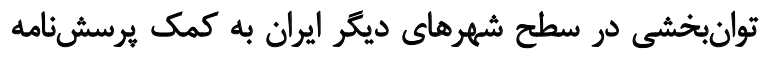

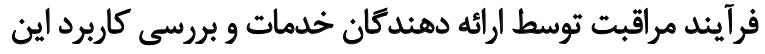

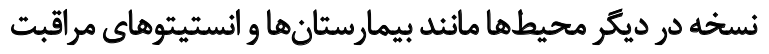

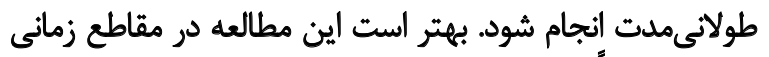

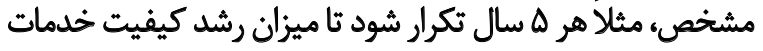

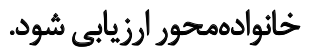

مالاحظاث اخلاقي

بيروى أز اصول اخلاق ثئوهش

اين مقاله از دانشكاه علوم يزشكى اراك تأييديه كميته اخلاق باكد

IR.ARAKMU.REC.1397.167

$$
\text { ماهي مالي }
$$

اين مقاله استخراج شده از طرح تحقيقاتى در دانشكاه علوم

$$
\text { مشاركت نويسى اراك است. }
$$

همه نويسند كان در آمادهسازى اين مقاله مشاركت داشتهاند.

$$
\text { تثار مثنافع }
$$

بنابر اظهار نويسندكان، اين مقاله تعارض منافع ندارد. 


\section{References}

[1] Dalvand H, Rassafiani M, Bagheri H. [Family centered approach: A literature the review (Persian)]. Journal of Modern Rehabilitation. 2014; 8(1):1-9.

[2] Dunst CJ. Family-centered practices birth through high school. The Journal of Special Education. 2002; 36(3):141-9. [DOI:10.1177/002 24669020360030401]

[3] Trivette CM, Dunst CJ, Allen S, Wall L. Family-centeredness of the Children's Health Care journal. Children's Health Care. 1993; 22(4):241-56. [DOI:10.1207/s15326888chc2204_1] [PMID]

[4] Law M, Teplicky R, King S, King G, Kertoy M, Moning T, et al. Family-centred service: moving ideas into practice. Child: Care, Health and Development. 2005; 31(6):633-42. [DOI:10.1111/j.13652214.2005.00568.x]

[5] Teymouri F, Alhani F, Kazemnejad A. [The effect of family-centered empowerment model on the Quality of life of the parents of children with asthma (Persian)]. Scientific Journal of Hamadan Nursing \& Midwifery Faculty. 2011; 22(3):5-14.

[6] Law M, Darrah J, Pollock N, King G, Rosenbaum P, Russell D, et al. Family-centred functional therapy for children with cerebral palsy: An emerging practice model. Physical \& Occupational Therapy in Pediatrics. 1998; 18(1):83-102. [DOI:10.1080/J006v18n01_06]

[7] Allen RI, Petr CG. Toward developing standards and measurements for family-centered practice in family support programs. In: Singer GHS, Powers LE, Olson AL. editors. Family, Community \& Disability Series, Vol. 1. Redefining Family Support: Innovations in Public-Private Partnerships. Baltimore: Paul H Brookes Publishing; 1996.

[8] Rosenbaum P, King S, Law M, King G, Evans J. Family-centred service: A conceptual framework and research review. Physical \& Occupational Therapy in Pediatrics. 1998; 18(1):1-20. [DOI:10.1080/ J006v18n01_01]

[9] Lammi BM, Law M. The effects of family-centred functional therapy on the occupational performance of children with cerebral palsy. Canadian Journal of Occupational Therapy. 2003; 70(5):285-97. [D OI:10.1177/000841740307000505] [PMID]

[10] Matin Sadr N, Haghgoo HA, Samadi SA, Rassafiani M, Bakhshi E. Impact of air seat cushions and ball chairs on classroom behavior of students with autism spectrum disorder (Persian). Archives of Rehabilitation. 2016; 17(2):136-47. [DOI:10.21859/jrehab-1702136]

[11] Dalvand H, Rassafiani M, Hosseini SA, Samadi SA, Khankeh HR. [Concept analysis of occupational therapy handling in the children with cerebral palsy: A hybrid model (Persian)]. Archives of Rehabilitation. 2015; 16(2):110-9.

[12] Shoja'ei-Zadeh D, Rassafiani HR. [A Study on depression among pre-university students Kazeron City 2000-2001 (Persian)]. Archives of Rehabilitation. 2001; 2(3):29-32.

[13] Nobakht Z, Rassafiani M, Rezasoltani P, Sahaf R, Yazdani F. Environmental barriers to social participation of children with cerebral palsy in Tehran. Iranian Rehabilitation Journal. 2013; 11(Special issue):40-5.

[14] Rassafiani M, Sahaf R. Hypertonicity in children with cerebral palsy: A new perspective. Iranian Rehabilitation Journal. 2011; 9(Special issue):66-74.
[15] Nobakht Z, Rassafiani M, Reza Soltani P. Validity and reliability of Persian version of Craig Hospital Inventory of Environmental Factors (CHIEF) in children with cerebral palsy. Iranian Rehabilitation Journal. 2011; 9(1):3-10

[16] Stefánsdóttir S, Thóra Egilson S. Diverging perspectives on children's rehabilitation services: a mixed-methods study. Scandinavian Journal of Occupational Therapy. 2016; 23(5):374-82. [DOI:1 0.3109/11038128.2015.1105292] [PMID]

[17] Asai H. Predictors of nurses' family-centered care practises in the neonatal intensive care unit. Japan Journal of Nursing Science. 2011; 8(1):57-65. [DOI:10.1111/j.1742-7924.2010.00159.x] [PMID]

[18] Concepcion M, Murphy S, Canham D. School nurses' perceptions of family-centered services: Commitment and challenges. The Journal of School Nursing. 2007; 23(6):315-21. [DOI:10.1177/105 98405070230060301] [PMID]

[19] Christon LM, Myers BJ. Family-centered care practices in a multidisciplinary sample of pediatric professionals providing autism spectrum disorder services in the United States. Research in Autism Spectrum Disorders. 2015; 20:47-57. [DOI:10.1016/j. rasd.2015.08.004]

[20] Siebes RC, Ketelaar M, Wijnroks L, van Schie PE, Nijhuis BJ, Vermeer A, et al. Family-centred services in the Netherlands: validating a self-report measure for paediatric service providers. Clinical Rehabilitation. 2006; 20(6):502-12. [DOI:10.1191/0269215506cr979oa] [PMID]

[21] Soleymani Z, Joveini G, Baghestani AR. The communication function classification system: Cultural adaptation, validity, and reliability of the Farsi version for patients with cerebral palsy. Pediatric Neurology. 2015; 52(3):333-7. [DOI:10.1016/j.pediatrneurol.2014.10.026] [PMID]

[22] Riyahi A, Rassafiani M, Akbar Fahimi N, Sahaf R, Yazdani F. Crosscultural validation of the Persian version of the Manual Ability Classification System for children with cerebral palsy. International Journal of Therapy and Rehabilitation. 2013; 20(1):19-24 [DOI:10.12968/ijtr.2013.20.1.19]

[23] King S, Rosenbaum PL, King G. The Measure of Processes of Care: A means to assess family-centred behaviours of health care providers. Hamilton: McMaster University; 1995.

[24] Woodside J, Rosenbaum P, King S, King G. Measure of Processes of Care for service providers (MPOC-SP). Hamilton: McMaster University; 1998

[25] Siebes RC, Nijhuis BJ, Boonstra AM, Ketelaar M, Wijnroks L, Reinders-Messelink HA, et al. Measure Of Processes of Care For Service Providers (MPOC-SP). In: Bianca GJ, editor. Team Collaboration in Dutch Paediatric Rehabilitation. Groningen: University of Groningen; 2007.

[26] Himuro N, Miyagishima S, Kozuka N, Tsutsumi H, Mori M. Measurement of family-centered care in the neonatal intensive care unit and professional background. Journal of Perinatology. 2015; 35(4):284-9. [DOI:10.1038/jp.2014.204] [PMID]

[27] Bjerre I, Larsson $M$, Franzon AM, Nilsson $M$, Strömberg $G$, Westbom L. Measure of Processes of Care (MPOC) applied to measure parent's perception of the habilitation process in Sweden. Child: Care, Health and Development. 2004; 30(2):123-30. [DOI:10.1111/ j.1365-2214.2003.00403.x] 
This Page Intentionally Left Blank 